\title{
Age of the Mother as a Risk Factor and Timing of Hypospadias Repair According to Severity
}

\author{
Juan C. Jorge ${ }^{1 *}$, Marcos R. Pérez-Brayfield ${ }^{2}$, Camille M. Torres ${ }^{3}$, Coriness Piñeyro-Ruiz ${ }^{4}$, and \\ Naillil Torres ${ }^{5}$ \\ ${ }^{1}$ Department of Anatomy and Neurobiology, Officer of Diversity and Inclusion, School of Medicine, University of Puerto Rico, San Juan, Puerto Rico, USA \\ ${ }^{2}$ Division of Urology, School of Medicine, University of Puerto Rico, San Juan, Puerto Rico, USA \\ ${ }^{3} \mathrm{MD}$ program, School of Medicine, University of Puerto Rico, San Juan, Puerto Rico, USA \\ ${ }^{4}$ Department of Anatomy and Neurobiology, PhD Program, School of Medicine, University of Puerto Rico, San Juan, Puerto Rico, USA \\ ${ }^{5}$ Biology Program, Rio Piedras Campus, University of Puerto Rico, San Juan, Puerto Rico, USA
}

Received: March 09, 2016; Accepted: April 23, 2016; Published: April 29, 2016

*Corresponding author: Juan Carlos Jorge, Department of Anatomy and Neurobiology, Officer of Diversity and Inclusion, School of Medicine, University of Puerto Rico, San Juan, Puerto Rico, USA, Tel: +787-758-2525/1506; Fax: +787-766-0788; E-mail ID: juan.jorge@upr.edu

\begin{abstract}
Hypospadias is characterized by a displacement of the urethral opening in males that can change from the typical position within the glans penis to a subcoronal position (Type I), to anywhere along the ventral shaft (Type II), to penoscrotal, scrotal, or perineal positions (Type III). We and others have previously reported that age of the mother ( $\geq 40$ years old) is a risk factor for having a child with hypospadias, but there is a scarcity of reports on whether such risk is higher for having a child with the mild (Type I) or the more severe forms (Types II and III). In addition, we aimed to assess the timing of hypospadias repair according to severity.
\end{abstract}

Methods: Parents of children with hypospadias were interviewed by using a series of questionnaires ( $\mathrm{n}=128$ cases). Severity was confirmed in the clinic and age of the mother was self-reported. Number of surgeries, age of child by the first and the last intervention was also assessed. Ordered logistic regression and the Brant test were employed to calculate risk between mild (Type I) and severe cases (Types II and III), and the assumption of proportional odds, respectively. The Mann-Whitney U Test was used to compare number of surgeries and age by the last repair between mild and severe cases. One-way ANOVA was employed to compare age of the child at the time of first surgery across severities (Types I - III).

Results: Women $\geq 40$ years of age are 3.89 times (95\% CI: 1.20-12.64) at a higher risk for having a child with the more severe forms of the condition than younger women. Repair of Type I was accomplished with 1 intervention whereas more severe cases required 1-4 (2 \pm 0.5 ) surgical interventions. The timing for hypospadias repair of Type I cases occurred at an average age of $16.2 \pm 4.88$ months, of Type II cases occurred at an average age of $20.3 \pm 8.15$ months whereas the average age of the first hypospadias repair among Type III cases was $12.68 \pm 2.52$ months. Number of surgeries according to severity $(p \leq 0.0018$, z-ratio $=2.91)$ and age difference for the timing of last repair $(p \leq 0.045, \mathrm{z}$-ratio $=1.69)$ were statistically different, but not the age difference for the first repair.

Conclusions: Increased maternal age is associated with the most severe forms of hypospadias. There is room for improvement for the timing of hypospadias repair according to severity.

Keywords: Hypospadias; Hypospadias repair; Hypospadias severity; Hypospadias risk; Maternal age

\section{Introduction}

Hypospadias is a male congenital condition that is characterized by a displacement of the urethral opening. Position of the opening can change from the typical anatomical location within the glans penis to a subcoronal position (Type I), to anywhere along the ventral shaft (Type II), to penoscrotal, scrotal, or perineal positions (Type III). This urogenital condition is often diagnosed at birth, even though three dimensional ultrasound is able to detect it in-utero by the end of the second trimester [1-2].

It is a tenet in human embryology that the etiology of most congenital conditions is due to multifactorial factors or that most conditions are idiopathic. A leading clinical embryology textbook estimates that less than a quarter of congenital conditions are produced by known factors such as chromosomal variations, mutant genes, or environmental agents [3]. Hypospadias is not the exception; only a small proportion of cases have been linked to specific genes or environmental contaminants [4]. The twohit hypothesis proposes that genetic susceptibility linked to environmental exposure increases hypospadias risk [5-6]. It has been long recognized that age of the mother is one of the factors that defines a high-risk pregnancy in terms of reaching a healthy full-term pregnancy but also in terms of the potentiated risk for having a child with a congenital condition [7]. In fact, age of the mother ( $>40$ years of age) is associated to hypospadias risk [813]. In this study, we revisited the reported association between 
age of the mother and the risk of having a child with hypospadias, but according to severity of the condition.

Current standards of care recommend surgical repositioning of the urethral meatus between 6 and 18 months of life [14-17]. There have been a number of arguments to support such standard, some of them include: to favor positive surgical outcomes, anesthetic considerations, to favor a positive body image of the patient, and to favor sexual-and cognitive-development of the patient [18]. The notion here is that milestones of psychosexual development are related to self-awareness of the genitals; a mental process that is believed to begin around 18 months of life [19]. Therefore, we also aimed to determine the number and timing of hypospadias surgeries according to severity of the condition. The ultimate goal is to be able to establish an interprofessional algorithm to facilitate timely referral of hypospadias cases to pediatric urology.

\section{Methods}

Parents of children with hypospadias were interviewed using a series of questionnaires in three pediatric urology clinics (n = 128 cases) between October 2012 to October 2015. Severity was confirmed in the clinic and age of the mother was selfreported. The distribution of cases according to severity was as follows: Type I $(\mathrm{n}=64)$, Type II $(\mathrm{n}=28)$, and Type III $(\mathrm{n}=$ 36). We assessed the number of surgeries and age of child by the first and the last surgery. For analyses pertaining to age of the mother, number of surgeries, and age by the last surgery, cases were grouped according to "mild" (Type I) or "severe" (Types II and III) hypospadias. Timing of first repair was analyzed across severities.

All surgeries were planned as single or staged procedure at the beginning of the procedure based on the meatal position and degree of chordee. Surgeries were conducted by a single board certified pediatric urologist (MRP-B), which allowed us to complement questionnaire data with clinical record data for age of the infant by the first surgery.

\section{Statistical analysis}

Ordered logistic regression and the Brant test were employed to asses risk and the assumption of proportional odds, respectively. The Mann-Whitney U Test was used to compare number of surgeries and age by last surgical repair between mild (Type I) and severe cases (Types II and III). One-way ANOVA was employed to compare age of the child at the time of first surgery across severities (Types I-III). Data is expressed as average values + standard error of mean. Statistical significance was attained at $p<0.05$.

\section{Results}

Table 1 shows that women $>40$ years of age are 3.89 times (95\% CI: 1.20-12.64) at a higher risk for having a child with the more severe forms of hypospadias than women $<40$ years of age $(\mathrm{n}=128)$. The proportional odds assumption was met $\left(\mathrm{Chi}^{2}=\right.$ $0.27, p=0.601$ ), indicating that the risk is greater for the severe forms (Types II and III >Type I).
Figure 1A shows that surgical repair of mild cases was accomplished with 1 intervention whereas more severe cases required 1-4 $(2+0.5)$ surgical interventions. Number of

\begin{tabular}{|l|l|l|}
\hline \multicolumn{2}{|c|}{ Table 1: Age of the mother as a risk factor for severe hypospadias. } \\
\hline Age of the mother & $\begin{array}{l}\text { Odds Ratio } \\
\text { (Types II and III > Type I) }\end{array}$ & Confidence Interval \\
\hline$\geq$ 40 years of age & $\mathbf{3 . 8 9}$ & $\mathbf{1 . 2 0}-\mathbf{1 2 . 6 4}$ \\
\hline
\end{tabular}
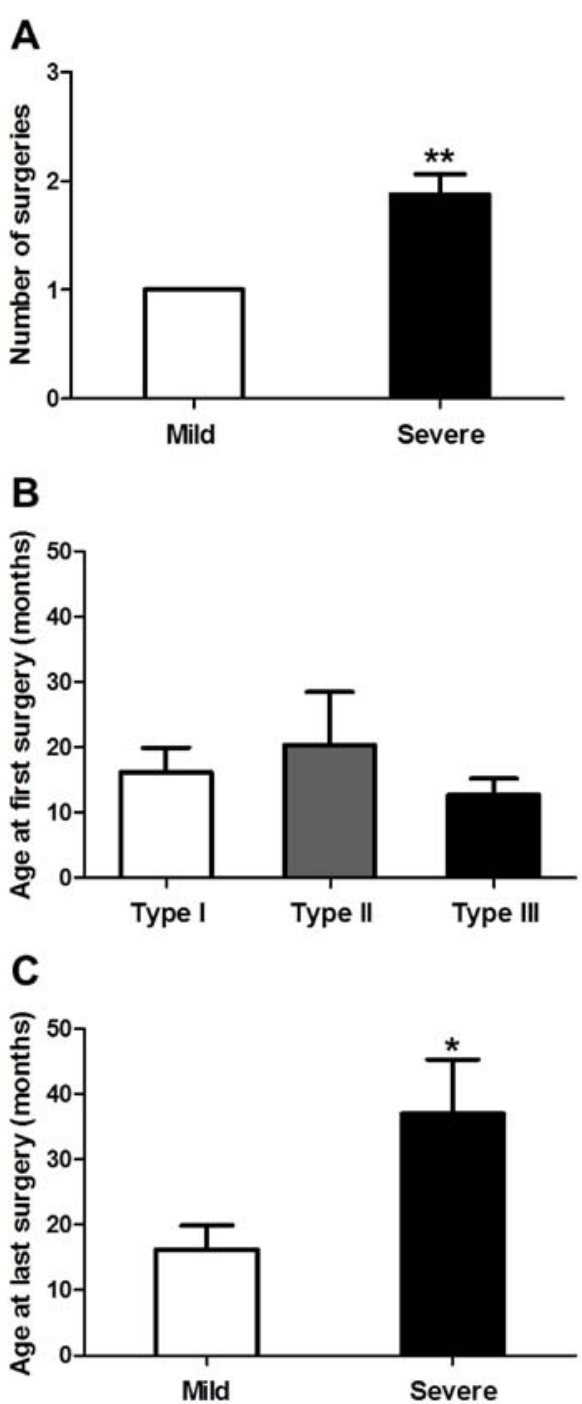

Figure 1: Number and timing of surgeries according to hypospadias severity.

Panel A: Surgical repair of Type 1 (mild) cases was accomplished with one intervention whereas Types II and III (severe) cases required two or more interventions.

Panel B: Age of the child (in months) at the time of the first surgical repair among Type I (white), Type II (grey), and Type III cases (black) are shown.

Panel C: Age of the child (in months) at the time of the last surgical repair among Type I (mild) cases versus Types II and III (severe) cases are shown. Data is expressed as average \pm SEM; $" ~ p \leq 0.0018 ;{ }^{*} p \leq 0.045$. See text for details. 
surgeries according to severity was statistically different ( $p<$ 0.0018 , z-ratio $=2.91$ ). Figure $1 \mathrm{~B}$ shows that hypospadias repair of Type I cases occurred at an average age of $16.2+4.88$ months, of Type II cases occurred at an average age of $20.3+8.15$ months whereas the average age of the first hypospadias repair among Type III cases was $12.68+2.52$ months. This age difference for hypospadias repair was not statistically significant (Figure 1B; F $(2,58)=0.6014, p=0.5516)$. We aimed to compare the time taken to surgically manage mild versus severe cases. Figure $1 \mathrm{C}$ shows that hypospadias repair of mild cases occurred at an average age of $16.2+4.88$ months whereas average age by the last repair of severe cases was $37+10.25$ months. This age difference was significant $(p<0.045$, z-ratio $=1.69)$.

\section{Discussion}

We have found that $>40$ years old mothers are 3.89 times more likely to have a child with the most severe forms of hypospadias than younger mothers. This is consistent with previous reports. A case-control population study in Sweden for the time period 1983-1993 found that the odds ratio (OR) of having a child with hypospadias among mothers $>40$ years of age was 1.30 with a 95\% Confidence Interval (CI) between 0.672.53 [8]. In the USA, it has been reported that OR for mothers > 35 years of age in the state of California was 1.2 (95\% CI: 1.11.4) for the time period 1983-89, whereas the odds of having a child with severe hypospadias for years 1990- 95 in that state was 1.5 (95\% CI: 1.2-1.7) [9]. The same study established that the OR for the state of New York was 1.2 (95\% CI: 1.1-1.3) for years 1983-96 [9]. In the case of Washington State (1987-1997), OR for mothers $>40$ years of age was 1.70 (95\% CI: 1.17-2.48) [10]. Data from the National Birth Defects Prevention Study (NBDPS), which includes the states of Arkansas, California, Georgia, Iowa, Massachusetts, New Jersey, New York, North Carolina, Texas, and Utah, revealed that mothers $\geq 35$ years were 2.1 times more likely to have a newborn with hypospadias than women $<25$ years of age (OR: 2.1, 95\% CI: 1.5-2.8) between the years of 1997 to 2000 [11]. Another study that employed the NBDPS database, a positive association was found for advanced maternal age ( $>$ 40 years) and hypospadias between the years of 1997 to 2007 (OR: 2.0, 95\% CI: 1.4-3.0) [12]. In Puerto Rico, data from the Birth Defects Prevention and Surveillance System of the Department of Health of Puerto Rico (2007-10) revealed an OR of 2.77 (95\% CI: 1.26-6.13) for $>40$ years old mothers [13]. Taken together, it is becoming increasingly clear that advanced maternal age is associated to hypospadias. Our finding is also consistent with previous studies showing that the risk is higher for having a child with hypospadias Type II or III than for Type I $[9,20,21]$. But the exact nature of this association still needs to be determined; is it related to genetic defects associated to aging, to subfertility, or any other factor? In spite of this uncertainty, it is reasonable to consider whether pregnancies of mothers older than 40 years of age ought to be monitored with ultrasonography in order to rule out hypospadias.

Although prenatal ultrasound is commonly used to determine sex of the fetus, it is not routinely used to study the anatomy of the genitals. Two echogenic lines at the tip of a blunt-ended penis can be used as the sonographic feature of hypospadias [22,23]. The echogenic lines represent the prepuce lateral folds. Another anatomical feature is the "tulip sign", which is formed by a ventrally oriented penis that is located between the scrotal folds [24]. These features are best seen in the late second trimester of pregnancy. However, it is important to note that even during the second trimester, it is a challenge to distinguish between typical female anatomy and severe penoscrotal hypospadias with ultrasonography [2]. Three dimensional ultrasonography is recommended to confirm diagnosis in these cases [1].

There is great need for prospective randomized trial studies that exclude confounding factors associated to surgery in order to unequivocally determine the ideal timing for hypospadias repair [18]. In our experience, we found that repair of mild cases was accomplished with 1 intervention at an average age of $16.2+4.88$ months whereas more severe cases required 1-4 $(2+0.5)$ surgical interventions with an average age at the last intervention of $37+10.25$ months. These differences were statistically significant. However, differences in the timing of the first repair were not detected as there was a wide spectrum of ages within each severity category. Timing of hypospadias repair can be affected by factors including, but not limited to, adequate penis size for surgery, parental preferences for surgery, poor adherence to treatment, among others. A deeper look into the reasons behind timing of repair is warranted. In clinical terms, it is important to bear in mind that severity of the condition can also be related to penis size, size and shape of the glans, presence and degree of penile curvature, histological quality of urethral plate, among other factors. All of these factors can also impact the best timing for hypospadias repair.

Studies show that surgical complications are minimized when hypospadias repair is done during early infancy $[25,26]$. Somewhat limited long-term psychosexual outcome data also supports the recommendation by American [14] and European [17] professional associations that early hypospadias repair is the best approach. Aside from the postulated psychological benefits of early repair [19,27], it has been argued that hypospadias surgery performed during adulthood does not indicate greater risk for urethroplasty complications [28]. This is not supported by other reports [29-31]. Based on bioethical principles, it has also been argued that hypospadias repair should only occur when the patient becomes able to participate in the decision-making process [32]. It has been difficult to assess the clinical algorithms for the management of hypospadias between institutions to establish quality indicators internationally [33]. Therefore, defined follow up intervals for data reporting in order to better evaluate surgical approaches, timing of hypospadias repair, and objective outcome measures are still needed [18,28,34].

\section{Conclusion}

There is cumulating evidence that older mothers are more likely to have a child with the most severe forms of hypospadias than younger mothers. Therefore, it would be advantageous to have counseling and referral algorithms in place to manage severe hypospadias cases when diagnosed during prenatal 
care. Irrespective of the unsettled ground with regard to the best timing for hypospadias repair, timely information and early referral to pediatric urology can help couples to better assess treatment options and to have real expectations about surgical outcomes [35]. We advocate for inter-professional communication between genetic counselors, psychologists, obstetricians, pediatricians and pediatric urologists to champion quality of service in urogenital care.

\section{Acknowledgements}

This publication was supported by the National Institute on Minority Health and Health Disparities of the National Institutes of Health under Award Number 2U54MD007587. The content is solely the responsibility of the authors and does not necessarily represent the official views of the National Institutes of Health. We acknowledge the collaboration of research team members during data collection and their so-authorship in preliminary data presentations in various scientific forums; Dr. Karina Escudero, Ana Ortiz, Juan G. Feliciano, Alex Colón, Joel Merced, Wilfredo Morales-Cosme, Héctor Navedo, and Andrés Pérez-Román.

\section{Declarations}

\section{Conflict of interest: N/A}

Ethical approval: This study received approval from the Institutional Review Board (protocol number A9000112).

\section{Clinical trial registration: N/A}

Source of support and disclaimer: This publication was supported by the National Institute on Minority Health and Health Disparities of the National Institutes of Health under Award Number 2U54MD007587. The content is solely the responsibility of the authors and does not necessarily represent the official views of the National Institutes of Health.

\section{References}

1. Rios LT, Araujo Júnior E, Nardozza LM, Rolo LC, Hatanaka AR, Moron $\mathrm{AF}$, et al. Prenatal diagnosis of penoscrotal hypospadia in third trimester by two- and three-dimensional ultrasonography: Case Rep Urol. 2012;2012:142814. doi: 10.1155/2012/142814.

2. Çayan F, Çayan S. Prenatal diagnosis of penoscrotal hypospadias and review of the literature. Turk J Urol. 2013;39(2):116-8. doi: 10.5152/ tud.2013.028

3. Moore KL, Persaud TVN, Torchia MG. Before we are born: Essentials of embryology and birth defects. 8th edition, Elsevier Sanuders: USA 2013.

4. Carmichael SL, Shaw GM, Lammer EJ. Environmental and genetic contributors to hypospadias: a review of the epidemiologic evidence. Birth Defects Res A Clin Mol Teratol. 2012;94(7):499-510. doi: 10.1002/bdra.23021

5. Baskin LS. Can we prevent hypospadias? J Pediatr Urol. 2007;3(6):4205. doi: 10.1016/j.jpurol.2007.07.007

6. Willingham E, Baskin LS. Candidate genes and their response to environmental agents in the etiology of hypospadias. Nat Clin Pract Urol. 2007;4(5):270-9.

7. Salmeen K, Zlatnik M. The oldest gravidas: a review of pregnancy risks in women over 45. Obstet Gynecol Surv. 2011;66(9):580-90. doi: 10.1097/OGX.0b013e318239125b.

8. Akre O, Lipworth L, Cnattingius S, Sparén P, Ekbom A. Risk factor patterns for cryptorchidism and hypospadias. Epidemiology. 1999;10(4):364-9.

9. Fisch H, Golden RJ, Libersen GL, Hyun GS, Madsen P, New MI, et al. Maternal age as a risk factor for hypospadias. J Urol. 2001;165(3):9346.

10. Porter MP, Faizan MK, Grady RW, Mueller BA. Hypospadias in Washington State: maternal risk factors and prevalence trends. Pediatrics. 2005;115(4): e495-e499. doi:10.1542/peds.2004-1552.

11. Carmichael SL, Shaw GM, Laurent C, Olney RS, Lammer EJ. The National Birth Defects Prevention Study. Maternal reproductive and demographic characteristics as risk factors for hypospadias. Paediatr Perinat Epidemiol. 2007;21(3):210-8.

12. Gill SK, Broussard C, Devine O, Green RF, Rasmussen SA, Reefhuis J, et al. The National Birth Defects Prevention Study. Association between maternal age and birth defects of unknown etiology - United States, 1997-2007. Birth Defects Res A Clin Mol Teratol. 2012;94(12):1010-8. doi: $10.1002 /$ bdra.23049.

13. Avilés LA, Alvelo-Maldonado L, Padró-Mojica I, Seguinot J, Jorge JC. Risk factors, prevalence trend, and clustering of hypospadias cases in Puerto Rico. J Pediatr Urol. 2014;10(6):1076-82. doi: 10.1016/j. jpurol.2014.03.014.

14.American Academy of Pediatrics. Timing of elective surgery on the genitalia of male children with particular reference to the risks, benefits, and psychological effects of surgery and anesthesia. Pediatrics. 1996;97(4):590-594.

15. Schultz JR, Klykylo WM, Wacksman J. Timing of elective hypospadias repair in children. Pediatrics. 1983;71(3):342-51.

16. Kelalis P, Bunge R, Barkin M, Perlmutter AD, Friedman DB, Work HH, Lucas $\mathrm{A}$. The timing of elective surgery on the genitalia of male children with particular reference to undescended testes and hypospadias. Pediatrics. 1975;56:479-483.

17. Tekgül S, Riedmiller H, Gerharz E, et al. Guidelines on paediatric urology. European Association of Urology, 2013.

18. Springer A, Baskin LS. Timing of hypospadias repair in patients with disorders of sex development. Endocrine Development. 2014;27:197202. doi: 10.1159/000363662.

19. Woodhouse CR, Christie D. Nonsurgical factors in the success of hypospadias repair. BJU International. 2005;96(1):22-27. doi: 10.1111/j.1464-410X.2005.05560.x.

20. Carmichael SL, Shaw GM, Nelson V, Selvin S, Torfs CP, Curry CJ. Hypospadias in California: trends and descriptive epidemiology. Epidemiology. 2003;14(6):701-706.

21.vanRooij IA, van der Zanden LF, Brouwers MM, Knoers NV, Feitz WF, Roeleveld N. Risk factors for different phenotypes of hypospadias: results from a Dutch case-control study. BJU International. 2013;112(1):121-128. doi: 10.1111/j.1464-410X.2012.11745.x.

22. Cafici D, Iglesias A. Prenatal diagnosis of severe hypospadias with two- and three-dimensional sonography. J Ultrasound Med. 2002;21(12):1423-1426.

23. Efrat Z, Perri T, Ramati E, Tugendreich D, Meizner I. Fetal gender assignment by first-trimester ultrasound. Ultrasound Obstet Gynecol. 2006;27(6):619-621. 
24. Meizner I, Mashiach R, Shalev J, Efrat Z, Feldberg D. The 'tulip sign' a sonographic clue for in-utero diagnosis of severe hypospadias. Ultrasound Obstet Gynecol. 2002;19(3):250-253.

25. Perlmutter AE, Morabito R, Tarry WF. Impact of patient age on distal hypospadias repair: A surgical perspective. Pediatric Urology. 2006;68(3):648-651.

26. Bermudez DM, Canning DA, Liechty KW. Age and pro-inflammatory cytokine production: Wound-healing implications for scar-formation and the timing of genital surgery in boys. Journal of Pediatric Urology. 2011;7(3):324-31. doi: 10.1016/j.jpurol.2011.02.013.

27. Jones BC, O'Brien M, Chase J, Southwell BR, Hutson JM. Early hypospadias surgery may lead to a better long-term psychosexual outcome. The Journal of Urology. 2009;182(4):1744-1749. doi: 10.1016/j.juro.2009.02.089.

28. Snodgrass W, Bush N. Recent advances in understanding/management of hypospadias. F1000Prime Reports. 2014;4;6:101. doi: 10.12703/ P6-101.

29. Hensle TW, Tennenbaum SY, Reiley EA, Pollard J. Hypospadias repair in adult: Adventures and misadventures. The Journal of Urology. 2001;165(1):77-79.
30. Adayener C, Akyol I. Distal hypospadias repair in adults: the results of 97 cases. Urologia Internationalis. 2006; 76(3): 247-251. doi:10.1159/000091628.

31. Bhat A, Bhat M, Kumar V, Kumar R, Mittal R, Saksena G. Comparison of variables affecting the surgical outcomes of tubularized incised plate urethroplasty in adult and pediatric hypospadias. J Pediatr Urol. 2016;12(2):108.e1-7. doi: 10.1016/j.jpurol.2015.09.005.

32. Carmack A, Notini L, Earp BD. Should surgery for hypospadias be performed before an age of consent? Journal of Sex Research. 2015;19:1-12. doi: 10.1080/00224499.2015.1066745.

33. Chrzan R, Dik P, Klijn AJ, de Jong TP. Quality assessment of hypospadias repair with emphasis on techniques used and experience of pediatric urologic surgeons. Urology. 2007;70(1):148-152.

34. Castagnetti M, El-Ghoneimi. Surgical management of primary severe hypospadias in children: Systematic 20-year review. The Journal of Urology. 2010;184(4):1469-1474. doi: 10.1016/j.juro.2010.06.044.

35. Pérez-Brayfield MR, Jorge JC, Avilés LA, Díaz J, Ortiz V, Morales-Cosme W. Concordance of expert and parental opinion about hypospadias surgical outcome is severity dependent. Frontiers in Pediatrics. 2016;4:2. doi: 10.3389/fped.2016.00002. 